\title{
Preventive effect of continuous cisternal irrigation with magnesium sulfate solution on angiographic cerebral vasospasms associated with aneurysmal subarachnoid hemorrhages: a randomized controlled trial
}

\author{
Takuji Yamamoto, MD, ${ }^{1}$ Kentaro Mori, MD, ${ }^{2}$ Takanori Esaki, MD, ${ }^{3}$ Yasuaki Nakao, MD, ${ }^{1}$ \\ Joji Tokugawa, MD, ${ }^{1}$ and Mitsuya Watanabe, MD'
}

'Department of Neurosurgery, Juntendo University Shizuoka Hospital, Izunokuni, Shizuoka; 2Department of Neurosurgery, National Defense Medical College, Tokorozawa, Saitama; and ${ }^{3}$ Department of Rehabilitation, Gifu Central Hospital, Gifu, Japan

\begin{abstract}
OBJECTIVE Although cerebral vasospasm (CV) is one of the most important predictors for the outcome in patients with subarachnoid hemorrhage (SAH), no treatment has yet been established for this condition. This study investigated the efficacy of continuous direct infusion of magnesium sulfate $\left(\mathrm{MgSO}_{4}\right)$ solution into the intrathecal cistern in patients with an aneurysmal SAH.
\end{abstract}

METHODS An SAH caused by a ruptured aneurysm was identified on CT scans within 72 hours after SAH onset. All patients were treated by surgical clipping and randomized into 2 groups: a control group of patients undergoing a standard treatment and a magnesium $(\mathrm{Mg})$ group of patients additionally undergoing continuous infusion of $5 \mathrm{mmol} / \mathrm{L} \mathrm{MgSO} \mathrm{H}_{4}$ solution for 14 days. The $\mathrm{Mg}^{2+}$ concentrations in serum and CSF were recorded daily. Neurological examinations were performed by intensive care clinicians. Delayed cerebral ischemia was monitored by CT or MRI. To assess the effect of the $\mathrm{Mg}$ treatment on $\mathrm{CV}$, the $\mathrm{CVs}$ were graded on the basis of the relative degree of constriction visible on cerebral angiograms taken on Day 10 after the $\mathrm{SAH}$, and transcranial Doppler ultrasonography was performed daily to measure blood flow velocity in the middle cerebral artery (MCA). Neurological outcomes and mortality rates were evaluated with the Glasgow Outcome Scale and modified Rankin Scale at 3 months after SAH onset.

RESULTS Seventy-three patients admitted during the period of April 2008 to March 2013 were eligible and enrolled in this study. Three patients were excluded because of violation of protocol requirements. The 2 groups did not significantly differ in age, sex, World Federation of Neurosurgical Societies grade, or Fisher grade. In the Mg group, the $\mathrm{Mg}^{2+}$ concentration in CSF gradually increased from Day 4 after initiation of the continuous $\mathrm{MgSO}_{4}$ intrathecal administration. No such increase was observed in the control group. No significant changes in the serum $\mathrm{Mg}^{2+}$ levels were observed for 14 days, and no cardiovascular complications such as bradycardia or hypotension were observed in any of the patients. However, bradypnea was noted among patients in the Mg group. The Mg group had a significantly better $\mathrm{CV}$ grade than the control group $(p<0.05)$. Compared with the patients in the Mg group, those in the control group had a significantly elevated blood flow velocity in the MCA. Both groups were similar in the incidences of cerebral infarction, and the 2 groups also did not significantly differ in clinical outcomes.

CONCLUSIONS Continuous cisternal irrigation with $\mathrm{MgSO}_{4}$ solution starting on Day 4 and continuing to Day 14 significantly inhibited $\mathrm{CV}$ in patients with aneurysmal $\mathrm{SAH}$ without severe cardiovascular complications. However, this improvement in $\mathrm{CV}$ neither reduced the incidence of delayed cerebral ischemia nor improved the functional outcomes in patients with SAH.

Clinical trial registration no.: UMIN000015760 (http://www.umin.ac.jp/ctr/index.htm)

http://thejns.org/doi/abs/10.3171/2015.1.JNS142757

KEY WORDS subarachnoid hemorrhage; magnesium; vasospasm; cisternal irrigation; vascular disorders

\footnotetext{
ABBREVIATIONS CV = cerebral vasospasm; $\mathrm{DCl}=$ delayed cerebral ischemia; $\mathrm{GCS}=$ Glasgow Coma Scale; $\mathrm{GOS}$ = Glasgow Outcome Scale; IQR = interquartile range; $\mathrm{MCA}=$ middle cerebral artery; $\mathrm{Mg}=$ magnesium; $\mathrm{MgSO}_{4}=$ magnesium sulfate; $\mathrm{Mg}^{2+}{ }_{\mathrm{CSF}}=\mathrm{Mg}^{2+}$ concentration in the $\mathrm{CSF} \mathrm{Mg}^{2+}{ }_{\text {serum }}=\mathrm{Mg}^{2+}$ concentration in the serum; $\mathrm{PaCO}{ }_{2}$ = partial pressure of carbon dioxide; $\mathrm{SAH}=$ subarachnoid hemorrhage; $\mathrm{TCD}=$ transcranial Doppler; WFNS = World Federation of Neurosurgical Societies. SUBMITTED December 7, 2014. ACCEPTED January 21, 2015. INCLUDE WHEN CITING Published online July 31, 2015; DOI: 10.3171/2015.1.JNS142757.

DISCLOSURE The authors report no conflict of interest concerning the materials or methods used in this study or the findings specified in this paper.
} 
$\mathrm{C}$ EREBRAL vasospasm $(\mathrm{CV})$ remains one of the major causes of high morbidity rates after an aneurysmal subarachnoid hemorrhage (SAH). ${ }^{7,15}$ Moreover, delayed cerebral ischemia (DCI) attributable to CV might be associated with the poor functional outcomes in patients with $\mathrm{SAH}{ }^{32}$ Many clinical approaches to treating $\mathrm{CV}$ have been investigated, but the interpretations of their results are varied and controversial. ${ }^{1,9}$ Consequently, no standard treatment for CV has yet been established.

Calcium-antagonist agents such as nimodipine, which produce vasodilation, may effectively treat patients with $\mathrm{CV}^{7,16}$ Recently, magnesium (Mg), which physiologically acts as a calcium antagonist, has also been suggested as a potential therapeutic agent for CV. ${ }^{16,18,19,32}$ Several groups have reported the efficacy of high-dose intravenous $\mathrm{Mg}$ administration after an aneurysmal SAH. ${ }^{3,29,40}$ High-dose intravenous $\mathrm{Mg}$ therapy has a vasodilatory effect, but increases the risk for exposure hypotension or hypoperfusion in patients with a CV. The $\mathrm{Mg}^{2+}$ levels in serum must be strictly maintained at $2.0-2.5 \mathrm{mmol} / \mathrm{L}$ to avoid cardiac complications. ${ }^{35,36}$ Intravenous $\mathrm{Mg}$ therapy did not affect functional outcomes after aneurysmal SAHs in Phase III trials, although several other clinical studies have demonstrated a benefit after an SAH. Results from the MASH (magnesium in aneurysmal subarachnoid hemorrhage) trial 2, a study of the effect of intravenous $\mathrm{Mg}$ infusion in patients with SAH, and from an updated meta-analysis of 7 randomized control trials have shown that intravenous $\mathrm{Mg}$ therapy did not improve clinical outcomes after an SAH. 5,6

Previously, we reported a new administration method in which magnesium sulfate $\left(\mathrm{MgSO}_{4}\right)$ solution is directly infused into the cistern and the CSF space. ${ }^{24}$ Intracisternal $\mathrm{MgSO}_{4}$ solution infusion has a vasodilatory effect on spastic cerebral arteries in animal models and improves reduced cerebral blood flow in an experimental model. ${ }^{23-27}$ Moreover, this infusion method was effective in a small group of patients with aneurysmal SAH. ${ }^{28}$ Direct $\mathrm{Mg}$ infusion into the CSF can achieve an effective $\mathrm{Mg}^{2+}$ concentration in the $\mathrm{CSF}\left(\mathrm{Mg}^{2+}{ }_{\mathrm{CSF}}\right)$ with a minimum required dosage of $\mathrm{Mg}$, but does not increase $\mathrm{Mg}^{2+}$ concentration in the serum $\left(\mathrm{Mg}^{2+}{ }_{\text {serum }}\right)$. Such an approach has the potential for dilating the cerebral vessels in SAH patients while avoiding the cardiac and systemic hypoperfusion complications associated with intravenous $\mathrm{Mg}$ infusion.

The present prospective randomized pilot study examined the effect of continuous intracisternal administration of $\mathrm{Mg}$ in patients with an aneurysmal SAH. We used transcranial Doppler (TCD) ultrasonography and cerebral angiography to assess the efficacy of intrathecal $\mathrm{Mg}$ infusion for preventing $\mathrm{CV}$ and monitored both $\mathrm{Mg}^{2+}$ serum and $\mathrm{Mg}^{2+}{ }_{\mathrm{CSF}}$ to assess the safety of this treatment. We also examined improvements in functional outcome in the patients undergoing this treatment relative to a control group of patients receiving standard treatment.

\section{Methods}

\section{Patient Selection}

The clinical trial protocol was reviewed and approved by the Juntendo University Shizuoka Hospital ethical committee. All patients or their legally authorized representatives provided written informed consent. This trial (no. UMIN000015760) is registered with the University Hospital Medical Information Network Clinical Trials Registry (http://www.umin.ac.jp/ctr/index.htm).

This study included data from 70 consecutive patients presenting with SAH from April 2008 to March 2013. The diagnosis of SAH was established on the basis of CT performed on admission within 72 hours after SAH onset. The etiology of the SAH was a ruptured aneurysm in all cases included here, because patients whose SAH was diagnosed as resulting from trauma, arteriovenous malformation, or other causes were excluded. All of the included patients underwent surgical clipping because patients treated with coil embolization were excluded. Other exclusion criteria included age older than 80 years, World Federation of Neurosurgical Societies (WFNS) Grade V $\mathrm{SAH}$, and major surgical complications identified by $\mathrm{CT}$ after surgery. Because patients with an SAH with a Fisher grade of 1 have a low incidence of $\mathrm{CV}$, which is not suitable for evaluating the preventive effects of a treatment on $\mathrm{CV}$, and because an intracerebral hematoma in patients with a Fisher Grade $4 \mathrm{SAH}$ has a strong influence on functional outcome, patients having an SAH with Grade 1 or Grade 4 were also excluded. Patients with pathological serum $\mathrm{Mg}$ levels, defined as less than $3.5 \mathrm{mmol} / \mathrm{L}$ or more than $7.0 \mathrm{mmol} / \mathrm{L}$ measured as ionized $\mathrm{Mg}$, were also excluded. ${ }^{14}$

The patients were randomized into 2 groups by a stratified block randomization method with the following factors: age, sex, and WFNS grade and Fisher grade and location of the SAH. The control group received a standard treatment with cisternal irrigation therapy, ${ }^{49}$ and the $\mathrm{Mg}$ group received continuous infusion of $\mathrm{MgSO}_{4}$ solution in addition to the standard treatment.

\section{Surgical Treatment and $\mathrm{MgSO}_{4}$ Infusion}

Patients were surgically treated within 72 hours after $\mathrm{SAH}$ onset and then received care under normovolemic and normotensive conditions. During direct clipping surgery, the Liliequist membrane was opened to allow CSF circulation between the supratentorial and infratentorial cisterns, and the cisternal drainage tube was placed into the basal cistern. A spinal drainage tube was also inserted through the lumbar spine immediately after the surgery. As a clot-lysis agent under our standard cisternal irrigation protocol, alteplase, $0.2 \mathrm{mg}$ (that is, recombinant tissuetype plasminogen activator; Mitsubishi Tanabe Pharma), was directly administered into the basal cistern via the cisternal drainage tube every 8 hours for 2 days. ${ }^{49}$ During administration of the clot-lysis agent, absence of hemorrhagic complications was confirmed by daily CT examinations. Normovolemia was maintained in all patients using Mg-free transfusions. Mild hypervolemia and induced hypertension was attempted in patients with deteriorating neurological status due to CV. Fasudil hydrochloride, 90 mg (Eril S; Asahi Kasei Pharma), was administered daily for 14 days. ${ }^{36,37}$

Continuous infusion of $\mathrm{MgSO}_{4}$ solution containing $5 \mathrm{mmol} / \mathrm{L}$ of $\mathrm{Mg}^{2+}$ was performed at $20 \mathrm{ml} / \mathrm{hr}$ from Day 4 
until Day 14 through the cisternal to spinal drainage. The cisternal drainage tube was connected to the pressurecontrol system via a $\mathrm{T}$ connector as a safety outlet. The overflow route was set at a height of $15 \mathrm{~cm} \mathrm{H}_{2} \mathrm{O}$ to avoid excessive infusion. All drainage catheters were carefully maintained to avoid complications such as overdraining or increased intracranial pressure during the irrigation (Fig. 1). ${ }^{28}$

The patients' basic vital signs were recorded daily or continuously during administration of the $\mathrm{MgSO}_{4}$ solution and included the following: blood pressure, heart rate, body temperature, oxygen saturation, arrhythmia, and blood gas levels. Partial pressure of oxygen and partial pressure of carbon dioxide $\left(\mathrm{PaCO}_{2}\right)$ were monitored daily by arterial gas analysis, and tracheal intubation was considered in the presence of bradypnea with a $\mathrm{PaCO}_{2}$ of over $60 \mathrm{~mm}$ $\mathrm{Hg}$. Blood samples were routinely taken for biochemical examination. $\mathrm{Mg}^{2+}$ serum and $\mathrm{Mg}^{2+}{ }_{\mathrm{CSF}}$ were monitored daily before, during, and after infusion of the $\mathrm{MgSO}_{4}$ solution with ion-selective electrodes (Critical Care Xpress; Nova Biomedical) for 14 days.

Neurological examination was performed by intensive care clinicians. Symptomatic CV was defined as clinical neurological deterioration attributable to a $\mathrm{CV}$, after exclusion of hydrocephalus, seizures, surgical invasion, or other causes. However, symptomatic CV was difficult to define only on the basis of clinical deterioration, particularly in comatose patients or in patients under sedation. Therefore, we defined low-density areas on CT images as symptomatic CV after other causes had been excluded by repeated postoperative CT examinations. ${ }^{11,12}$ The $\mathrm{CV}$ was diagnosed jointly with a neurosurgeon unaware of the clinical details who confirmed that a low-density area might be caused by a DCI after an SAH.

Angiography was repeated on Day 10 after the SAH to obtain data on the location and degree of $\mathrm{CV}$ during treatments in both control and $\mathrm{Mg}$ groups. The degree of $\mathrm{CV}$ constriction was assessed by comparing the CV findings on the Day 10 cerebral angiogram with those on the angiogram obtained on admission for the SAH. The CV on Day 10 was graded on a scale of 1 to 5 by a neurosurgeon unaware of the patient's clinical status as follows: Grade 1, mild constriction ( $\leq 20 \%)$; Grade 2, mild-tomoderate constriction (21\%-40\%); Grade 3, moderate constriction (41\%-60\%); Grade 4, moderate-to-severe constriction (61\%-80\%); and Grade 5, severe constriction $(\geq 81 \%) .{ }^{16}$ Angioplasty treatment by the balloon technique and chemical vasodilator agents were not used in any of the patients.

Transcranial Doppler ultrasonography was performed daily for 14 days after the surgery. Mean velocity was measured in the $\mathrm{M}_{1}$ segment of the middle cerebral artery (MCA) on the surgical side. The average of the velocity in the $\mathrm{M}_{1}$ MCA segment for the first 4 days was calculated

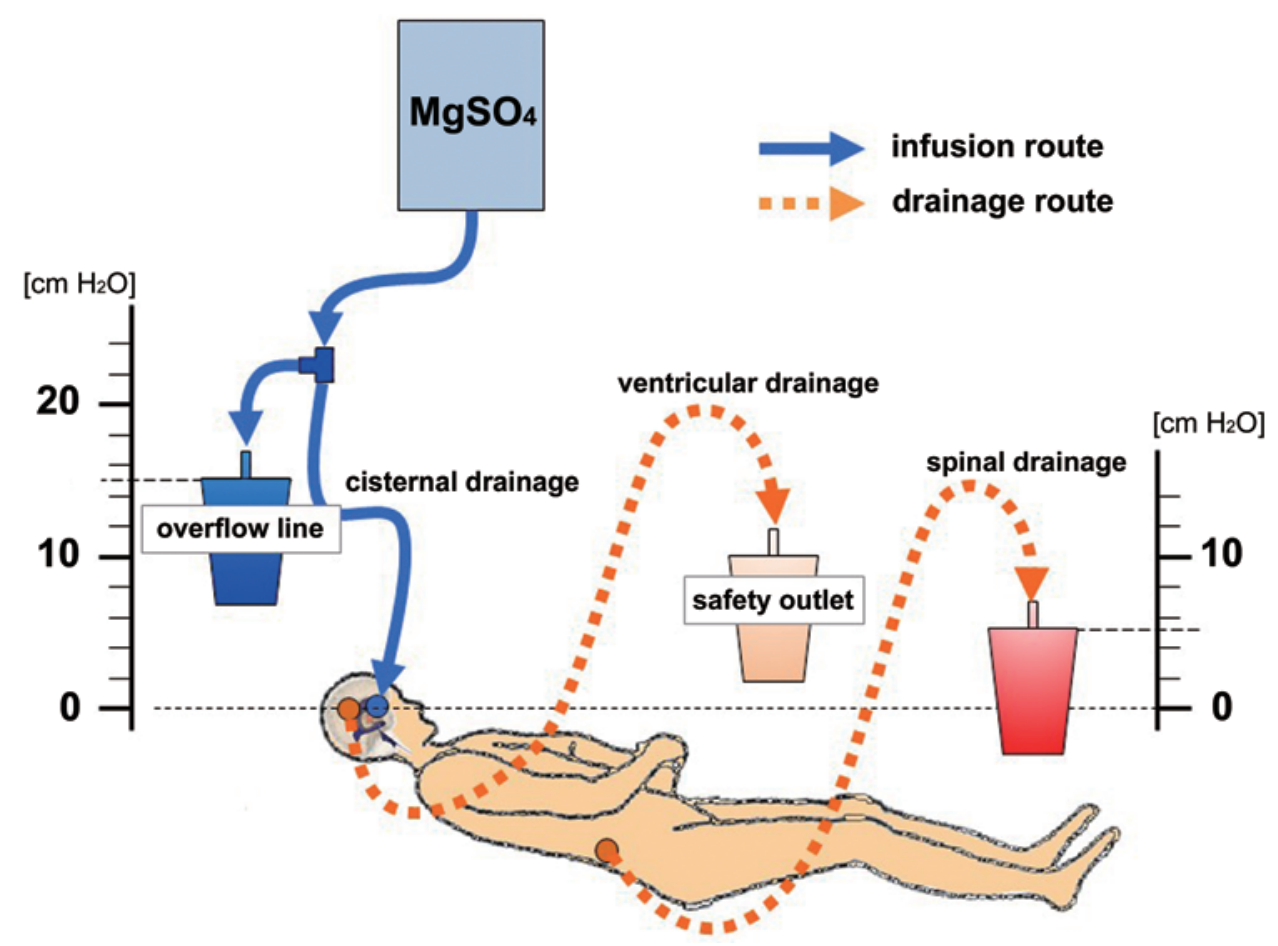

FIG. 1. Schematic of the cisternal Mg irrigation system used in this study. Through the cisternal drainage tube, $\mathrm{MgSO}_{4}$ solution (5 $\mathrm{mmol} / \mathrm{L}$ ) was continuously infused at $20 \mathrm{ml} / \mathrm{hr}$ into the subarachnoid space for 14 days. The overflow was set at a height of $15 \mathrm{~cm}$ $\mathrm{H}_{2} \mathrm{O}$ to avoid excessive infusion (indicated by the blue drainage bag). The irrigation fluid was mainly drained via a spinal drainage route. A ventricular drainage route acted as a safety outlet (indicated by the orange drainage bag) for emergencies when the intracranial pressure suddenly increased. The level of the drainage (indicated by the red drainage bag) was adjusted according to the drainage volume, which was recorded hourly. The 2 scale bars on both sides indicate the height of the drainage points measured from the external auditory meatus at $0 \mathrm{~cm} \mathrm{H}_{2} \mathrm{O}$. 
as the baseline velocity for each patient. For both groups, any changes in the MCA velocity measured on Days 5-14 was calculated as the percentage of the baseline velocity.

\section{Statistical Analysis}

Neurological outcomes and mortality rates were evaluated with scores on the Glasgow Outcome Scale (GOS) and modified Rankin Scale at 3 months after SAH onset. Average values for groups are given as mean \pm SD or as median and interquartile range (IQR). The data were analyzed with the chi-square test, Fisher exact test, or MannWhitney U-test. Statistical significance was defined as $\mathrm{p}$ $<0.05$.

\section{Results}

From April 2008 to March 2013, 263 patients with SAH caused by a ruptured aneurysm were treated at Juntendo University Shizuoka Hospital. Of these patients, 73 were eligible and enrolled in this study. However, 3 patients were later excluded, because of violation of protocol requirements in 1 case in the control group and because of an injection failure of the $\mathrm{MgSO}_{4}$ solution in 2 patients in the $\mathrm{Mg}$ group. The clinical data of the remaining 70 patients ( 35 patients in the control group and 35 patients in $\mathrm{Mg}$ group) are summarized in Table 1. No significant differences were detected between the 2 groups in age, sex, WFNS grade, or Fisher grade. All 70 patients were treated by surgical clipping, and the patients in the 2 groups had aneurysms in similar locations.

The temporal changes in $\mathrm{Mg}^{2+}$ serum and $\mathrm{Mg}^{2+}{ }_{\mathrm{CSF}}$ are shown in Fig. 2. In the control group, both $\mathrm{Mg}^{2+}{ }_{\mathrm{CSF}}$ and $\mathrm{Mg}^{2+}$ serum tended to decrease in the first 4 days, but no statistically significant changes in these 2 concentrations were observed during the 14-day measurement period in this group. In contrast, $\mathrm{Mg}^{2+}{ }_{\mathrm{CSF}}$ in the $\mathrm{Mg}$ group gradually increased from Day 4 after the start of continuous $\mathrm{MgSO}_{4}$ intrathecal administration, reached a plateau level on Day 6, and remained at similarly high levels until Day 14. $\mathrm{Mg}^{2+}$ serum in the $\mathrm{Mg}$ group also slightly increased from the baseline level, but was not significantly different from $\mathrm{Mg}^{2+}{ }_{\text {serum }}$ in the control group. No patient in either group required supplementation of $\mathrm{Mg}$ because of $\mathrm{Mg}$ deficiency.

No cardiovascular complications associated with $\mathrm{Mg}$ administration, such as bradycardia or hypotension, were observed in the $\mathrm{Mg}$ patients. However, a decline in consciousness and bradypnea possibly caused by the sedative effect of $\mathrm{Mg}$ were observed in this group. The Glasgow Coma Scale (GCS) score in the Mg group decreased with

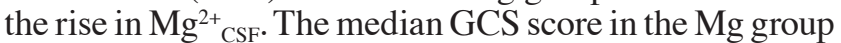
of 7 (IQR 7-13) was significantly lower than in the control group (median GCS score 15, IQR $14-15, \mathrm{p}<0.05$ ) on Day 10. Tracheal intubation was necessary in 23 patients (65.7\%) of the $\mathrm{Mg}$ group and in 11 patients (31.4\%) of the control group. Strict maintenance of the $\mathrm{PaCO}_{2}$ level in patients with increasing intracranial pressure resulted in no worsening of outcomes related to the bradypnea.

Angiographic examinations for CV after surgery were performed in 32 patients (91.4\%) in the $\mathrm{Mg}$ group and in 33 patients (94.3\%) in the control group. An angiography could not be performed in the other patients because of
TABLE 1. Characteristics of the patients in the Mg and control groups*

\begin{tabular}{|c|c|c|c|}
\hline \multirow[b]{2}{*}{ Characteristic } & \multicolumn{2}{|c|}{ Group } & \multirow[b]{2}{*}{$\mathrm{p}$ Value } \\
\hline & $\mathrm{Mg}$ & Control & \\
\hline No. of patients & 35 & 35 & \\
\hline Mean age in yrs & 59.1 & 59.5 & $0.859 \dagger$ \\
\hline Women, \% & 68.6 & 65.7 & $0.799 \ddagger$ \\
\hline Median WFNS grade & 2 & 2 & \\
\hline WFNS grade & & & $0.500 \S$ \\
\hline 1 & $8(22.9)$ & $9(25.7)$ & \\
\hline II & $18(51.4)$ & $20(57.1)$ & \\
\hline III & $2(5.7)$ & $1(2.9)$ & \\
\hline IV & $7(20.0)$ & $5(14.3)$ & \\
\hline V & $0(0.0)$ & $0(0.0)$ & \\
\hline Fisher grade of $\mathrm{SAH}$ & & & $0.680 \S$ \\
\hline 1 & $0(0.0)$ & $0(0.0)$ & \\
\hline 2 & $12(34.3)$ & $12(34.3)$ & \\
\hline 3 & $23(65.7)$ & $23(65.7)$ & \\
\hline 4 & $0(0.0)$ & $0(0.0)$ & \\
\hline SAH location & & & $0.416 \ddagger$ \\
\hline ACA & $19(54.3)$ & $14(40.0)$ & \\
\hline ICA & $10(28.6)$ & $15(42.9)$ & \\
\hline MCA & $6(17.1)$ & $5(14.3)$ & \\
\hline Other & $0(0.0)$ & $1(2.9)$ & \\
\hline Side of SAH & & & $0.075 \ddagger$ \\
\hline Left & $16(45.7)$ & $12(34.3)$ & \\
\hline Midline & $15(42.9)$ & $11(31.4)$ & \\
\hline Right & $4(11.4)$ & $12(34.3)$ & \\
\hline $\begin{array}{l}\text { ACA = anterior cerebral art } \\
\text { * The values in this table r } \\
\text { otherwise. } \\
\dagger \text { The } p \text { value was calculat } \\
\ddagger \text { The } p \text { value was calculat } \\
\S \text { The } p \text { value was calculat }\end{array}$ & $\begin{array}{l}C A=\text { internal } \\
\text { ent number } C \\
\text { th an unpaire } \\
\text { th a chi-squa } \\
\text { th a Mann-W }\end{array}$ & $\begin{array}{l}\text { tid artery. } \\
\text { ients (\%) un } \\
\text { st. } \\
\text { st. } \\
\text { y U-test. }\end{array}$ & indicated \\
\hline
\end{tabular}

renal dysfunction, allergy, or systemic conditions. The CV grade was significantly better in the $\mathrm{Mg}$ group (median grade of 2) than in the control group (median grade of $3)(p<0.05)$. None of the patients in the Mg group had a severe $\mathrm{CV}$ with a grade of 4 or 5 (Fig. 3).

Twenty-one patients $(60.0 \%)$ in the $\mathrm{Mg}$ group and 23 patients $(65.7 \%)$ in the control group underwent a TCD examination. Detection of the MCA or recording of continuous blood flow velocity in the MCA was difficult in some patients. The TCD ultrasonography results indicated that the velocity in the MCA increased more in the control group. In particular, the velocity was significantly higher in the control group than in the Mg group from Day 10 onward (Fig. 4).

A DCI identified on CT or MRI scans was observed in 9 patients $(25.7 \%)$ in the control group and in 5 patients (14.3\%) in the $\mathrm{Mg}$ group. Ischemic lesions attributable to a CV might be more common in the control group, and a more severe cerebral infarction might have occurred this group, but no significant differences were observed between the 2 groups. 


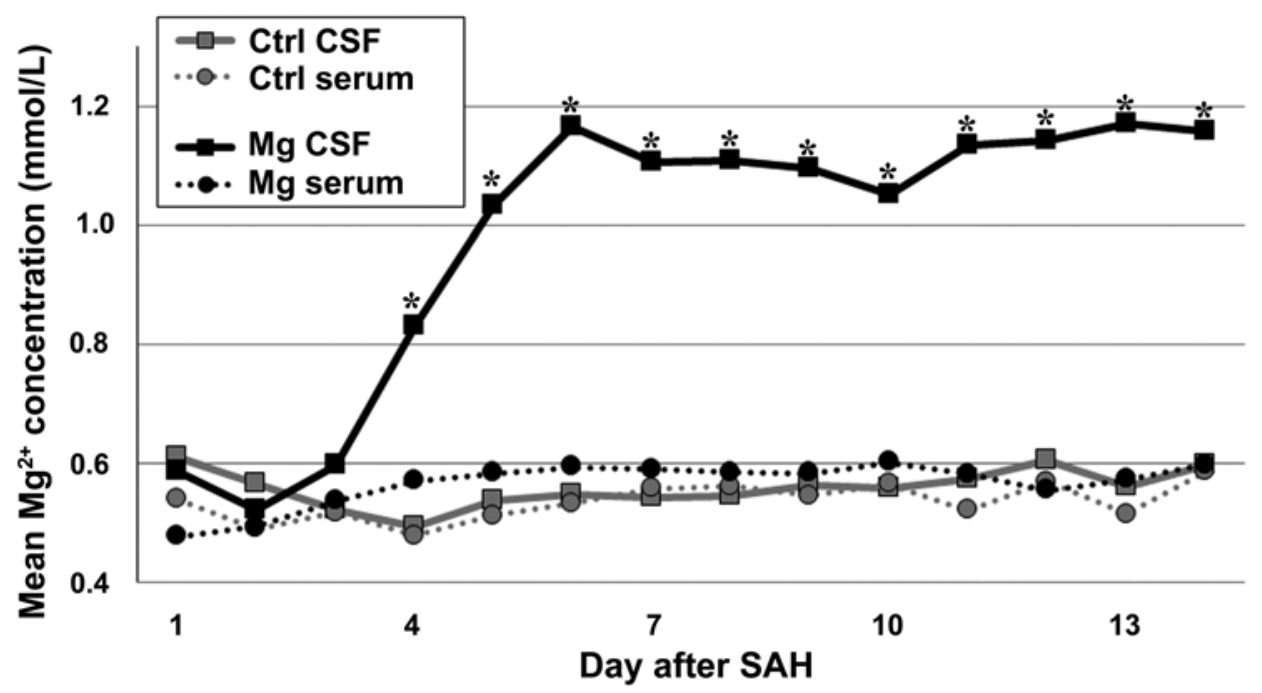

FIG. 2. Changes in $\mathrm{Mg}^{2+}$ concentration in both serum and CSF over time. The $\mathrm{Mg}^{2+}{ }_{\mathrm{CSF}}$ in the $\mathrm{Mg}$ group significantly increased from the $\mathrm{Mg}^{2+}{ }_{\mathrm{CSF}}$ at baseline after Day 4 and had plateaued by Day $6\left(\mathrm{Mg}^{2+}{ }_{\mathrm{CSF}}\right.$ marked by asterisks were statistically significantly different from the baseline concentration, $\mathrm{p}<0.05)$. The $\mathrm{Mg}^{2+}{ }_{\mathrm{CSF}}$ in the patients in the $\mathrm{Mg}$ group was also significantly different from the $\mathrm{Mg}^{2+}$ CSF in the patients in the control group on Days 4-14 ( $p<0.05$, repeated-measure ANOVA). The 2 patient groups did not significantly differ in $\mathrm{Mg}^{2+}{ }_{\text {serum }}(p>0.05)$. Ctrl CSF $=\mathrm{Mg}^{2+}{ }_{\mathrm{CSF}}$ in the control group; $\mathrm{Ctrl}$ serum $=\mathrm{Mg}^{2+}$ serum in the control group; $\mathrm{Mg}$ $\mathrm{CSF}=\mathrm{Mg}^{2+}{ }_{\mathrm{CSF}}$ in the $\mathrm{Mg}$ group; $\mathrm{Mg}$ serum $=\mathrm{Mg}^{2+}{ }_{\text {serum }}$ in the $\mathrm{Mg}$ group.

The clinical outcomes at the 3-month follow-up examination are shown in Table 2. Overall, the 2 groups did not significantly differ in these outcomes. Favorable outcomes indicated by modified Rankin Scale scores of 0-2 were observed for 28 patients $(80.0 \%)$ in the control group and for 27 patients (77.1\%) in the $\mathrm{Mg}$ group. A good outcome (scored as good recovery or moderate disability according to the GOS) was noted for 32 patients $(91.4 \%)$ in the control group and for 30 patients (85.7\%) in the Mg group. The 2 groups also had a similar rate of permanent shunt placement for hydrocephalus. The mortality rate was $2.9 \%$ in both 2 groups, with 1 patient dying in each group.

\section{Discussion}

The results of this study suggest that continuous cister- nal infusion with $\mathrm{MgSO}_{4}$ solution reduces the incidence of angiographic $\mathrm{CV}$ in patients with aneurysmal SAH, particularly of severe CVs with grades of 4 or 5 on our angiographic CV scale. Such findings might suggest a lower incidence of infarction in the $\mathrm{Mg}$ group; however, we note that our study protocol did not reduce the incidence of DCI and did not improve clinical outcomes among the patients.

Many experimental and clinical studies have demonstrated the vasodilatory effect of $\mathrm{Mg} .22,23,26,31,42$ For example, results from a meta-analysis have indicated that intravenous $\mathrm{Mg}$ administration exerts a vasodilatory effect on $\mathrm{CV}^{46}$ However, the recently conducted randomized controlled MASH-2 study failed to confirm that Mg infusion improves functional outcomes. ${ }^{5,6,46,48}$ Nonetheless, the physiological actions of $\mathrm{Mg}$ are probably important. ${ }^{30}$ To reach a CV via the blood route, $\mathrm{Mg}^{2+}{ }_{\text {serum }}$ needs to be

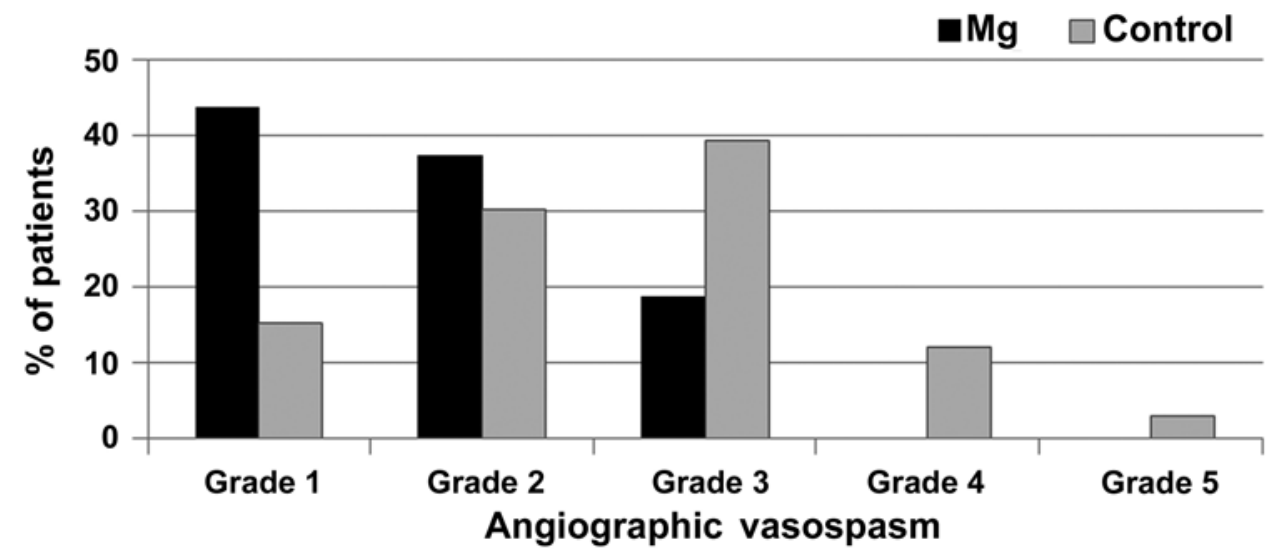

FIG. 3. The angiographic CV grades in the Mg and control groups on Day 10. The angiographic CV grades in the control group were on average significantly higher than those in the Mg group $(p<0.05$, Mann-Whitney U-test). Severe CVs (that is, those of Grade 4 or 5 on our angiographic CV scale) were not observed in the Mg group. 


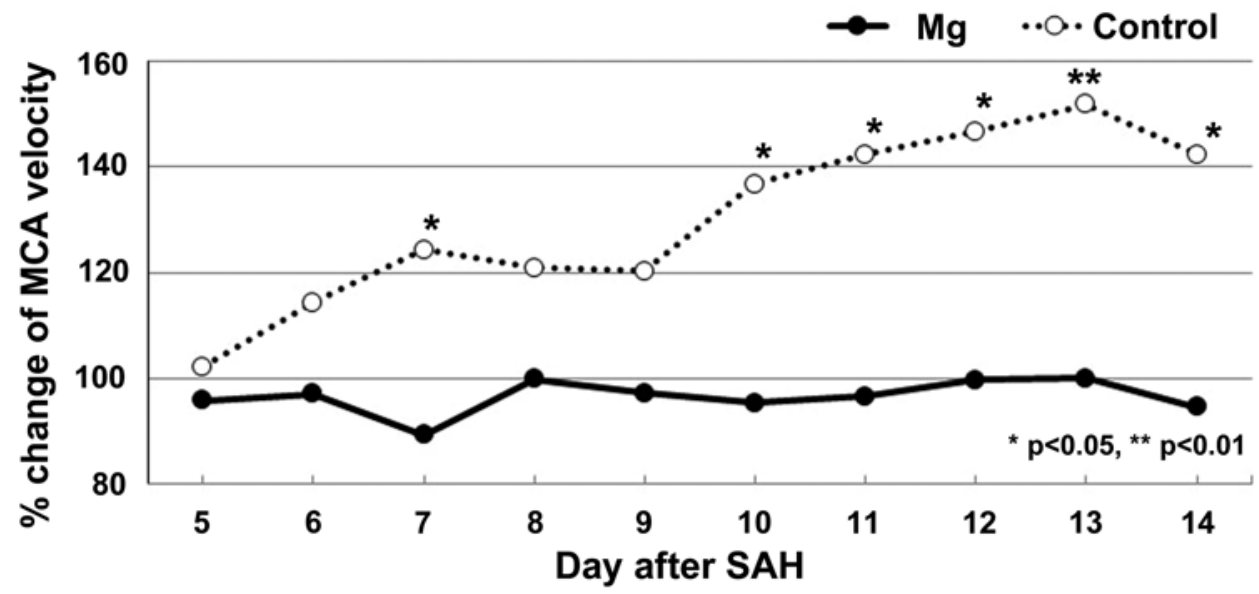

FIG. 4. Changes in MCA velocity over time in the Mg and control groups. The velocities were measured by TCD ultrasonography and are presented as percentages of the velocity at baseline (that is, the mean MCA velocity during the first 4 days after surgery determined for each patient). Compared with the MCA velocity in the Mg group, the MCA velocity in the control group increased significantly during the 10 -day period assessed, peaking at Day 13 . Statistically significant differences at the various time points between the 2 patient groups are indicated by asterisks above the velocity data for the control group.

TABLE 2. Summary of the clinical outcomes of the patients in this study at the 3-month follow-up*

\begin{tabular}{cccc}
\hline \multirow{2}{*}{ Variable } & \multicolumn{2}{c}{ Group } & \\
\cline { 2 - 3 } & $\mathrm{Mg}$ & Control & $\mathrm{p}$ Value \\
\hline mRS score & & & $0.322 \dagger$ \\
\hline 0 & $12(34.3)$ & $17(48.6)$ & \\
\hline 1 & $10(28.6)$ & $7(20.0)$ & \\
\hline 2 & $5(14.3)$ & $4(11.4)$ & \\
\hline 3 & $3(8.6)$ & $3(8.6)$ & \\
\hline 4 & $2(5.7)$ & $3(8.6)$ & \\
\hline 5 & $2(5.7)$ & $0(0.0)$ & \\
\hline 6 & $1(2.9)$ & $1(2.9)$ & \\
\hline GOS category & & & \\
\hline GR & $22(62.9)$ & $25(71.4)$ & \\
\hline MD & $8(22.9)$ & $7(20.0)$ & \\
\hline SD & $3(8.6)$ & $2(5.7)$ & \\
\hline VS & $1(2.9)$ & $0(0.0)$ & \\
\hline D & $1(2.9)$ & $1(2.9)$ & \\
\hline Favorable outcome, \% & & & \\
\hline mRS score of 0, 1, or 2 & 77.1 & 80.0 & $0.771 \ddagger$ \\
\hline GOS score of GR or MD & 85.7 & 91.4 & $0.452 \ddagger$ \\
\hline Patients requiring VPS/LPS, \% & 45.7 & 42.3 & $0.810 \ddagger$ \\
\hline Mortality rate, \% & 2.9 & 2.9 & $1.000 \ddagger$ \\
\hline Mean hospital LOS, days & 47.9 & 46.1 & $0.710 \S$ \\
\hline D & & \\
\hline
\end{tabular}

$\mathrm{D}=$ death; $\mathrm{GR}=$ good recovery; $\mathrm{LOS}=$ length of stay; $\mathrm{LPS}=$ lumboperitoneal shunt; $\mathrm{MD}=$ moderately disabled; $\mathrm{mRS}=$ modified Rankin Scale; $\mathrm{SD}=$ severely disabled; VPS = ventriculoperitoneal shunt; VS = vegetative state

* The values in this table represent number (\%) of patients unless indicated otherwise

† The $p$ value was calculated with a Mann-Whitney U-test.

$\ddagger$ The $p$ value was calculated with a chi-square test.

$\S$ The $p$ value was calculated with an unpaired t-test. maintained at high levels, because $\mathrm{Mg}$ translocates poorly across the blood-brain barrier. Any ensuing toxic effects of high $\mathrm{Mg}^{2+}{ }_{\text {serum }}$ can lead to various systemic complications such as arrhythmia, hypotension, or bradypnea. Accordingly, maintaining a $\mathrm{Mg}^{2+}$ serum optimal for the therapeutic window is extremely difficult because of the high risk for cardiovascular events. ${ }^{30,45}$

We have previously reported that the vasodilatory effect in intracranial arterial vessels may depend on $\mathrm{Mg}^{2+} \mathrm{CSF}^{25} \mathrm{In}$ contrast to intravenous $\mathrm{MgSO}_{4}$ injection, the direct cisternal infusion method used in the present study readily increases $\mathrm{Mg}^{2+}{ }_{\mathrm{CSF}}$ with a relatively small volume of $\mathrm{MgSO}_{4}$ solution. The findings in this study thus have demonstrated a safe infusion rate of $\mathrm{MgSO}_{4}$ solution for achieving a $\mathrm{Mg}^{2+}{ }_{\mathrm{CSF}}$ that results in optimal vasodilation. ${ }^{45}$ No adverse effect of $\mathrm{Mg}^{2+}$ on the cardiovascular system was observed, even though the intrathecal $\mathrm{MgSO}_{4}$ infusion slightly increased $\mathrm{Mg}^{2+}{ }_{\text {serum. }}$. This infusion method is relatively safe if the total infusion volume is adjusted such that it maintains a balance of the CSF drainage volume with that of the perfusion solution. Cisternal drainage is more invasive, but is one of the standard techniques in the surgical treatment of ruptured aneurysms. ${ }^{17,33,49}$ We propose that continuous cisternal infusion is no more invasive than conventional treatment of patients with SAH.

Recently, several studies have shown that DCI is not closely associated with $\mathrm{CV}$, suggesting that $\mathrm{CV}$ is not the only cause of DCI in patients with SAH. ${ }^{4,9}$ On the other hand, the occurrence of cerebral infarction is clearly associated with DCI, and cerebral infarction identifiable on CT or MRI scans is clearly associated with poor functional outcomes..$^{10} \mathrm{~A}$ DCI might be caused by several factors, including early brain injury, microthromboembolism, cortical spreading ischemia, cerebrovascular autoregulation dysfunction, and delayed effects of SAH-induced brain injury. ${ }^{2,8,9,13,35,44}$ Clinically, the infarction caused by severe $\mathrm{CV}$ is well known to occur in patients with SAH. The severity of $\mathrm{CV}$ is one of the independent predictors of a poor functional outcome. Therefore, preventing CV occurrence is important for patients with SAH. ${ }^{10,21}$ 
The results of the present study show that intracisternal Mg therapy significantly ameliorates angiographic CV but fails to improve clinical outcomes. Recently, despite indicating decreased occurrence of $\mathrm{CV}$ after treatment with clazosentan, a potent vasodilator acting as a selective endothelin A receptor antagonist, a Phase 3 clinical study (that is, the CONSCIOUS-2 trial) failed to show any effect of vasodilation on CV-related morbidity rates or on functional outcomes..$^{20}$ The results in this and other studies suggest that vasodilatory treatment alone may not sufficiently improve the clinical outcomes in SAH patients, so any new treatment modality should have both vasodilatory and neuroprotective effects. ${ }^{19,47} \mathrm{Mg}^{2+}$ not only acts as a vasodilator by blocking $\mathrm{Ca}^{2+}$ influx via the voltage-dependent calcium channels in the vascular smooth muscle but also acts as a neuroprotector by inhibiting glutamate and $\mathrm{N}$-methyl-D-aspartate receptors. . $^{18,27,39,41}$ We started intracisternal $\mathrm{Mg}$ infusion on Day 4 after the ictus, and $\mathrm{Mg}^{2+}{ }_{\mathrm{CSF}}$ reached a plateau on Day 6. We therefore hypothesize that our intracisternal $\mathrm{Mg}$ infusion protocol might not have been initiated early enough to prevent DCI-related brain injuries such as early brain injury and cortical spreading ischemia. On the basis of these results, we are planning to conduct another randomized controlled trial of intracisternal $\mathrm{Mg}$ therapy starting immediately after clipping surgery. ${ }^{38}$

In this study, the level of observed sedation depended on $\mathrm{Mg}^{2+}{ }_{\mathrm{CSF}}$, and respiratory depression also emerged. The sedative effect of $\mathrm{Mg}^{2+}$ might improve the cerebral metabolic rate of oxygen and may provide neuroprotection. ${ }^{27,43}$ Although respiratory depression might not worsen a $\mathrm{CV}$ if airway conductivity and oxygenation levels remain normal, it is not a safe clinical sign. Moreover, respiratory depression requiring tracheal intubation might provoke systemic complications such as pneumonia, cardiac failure, or malnutrition. We considered that these negative effects would offset the potential benefits of our intracisternal Mg therapy.

Although the present study failed to indicate that the $\mathrm{Mg}$ treatment statistically significantly improved functional outcomes, we note the favorable outcomes in $80 \%$ of the patients in the control group, a rate that was higher than the rates reported from other randomized controlled trials. ${ }^{5,30,34,45} \mathrm{~A}$ selection bias that arose from our exclusion of patients with an SAH with a Fisher grade of 4, a WFNS grade of $\mathrm{V}$, or with severe surgical complications should also be considered in the interpretation of our results. We also note that continuous irrigation with $\mathrm{MgSO}_{4}$ solution has been previously shown not to improve functional outcomes compared with several treatments including administration of fasudil hydrochloride (a Rho kinase antagonist), cisternal irrigation therapy with tissue-plasminogen activator, and others. ${ }^{30,38}$ Last, the present study was a single-center trial, with too few cases to evaluate the functional outcome in SAH attributed to multifactorial etiologies.

\section{Conclusions}

The results of the present study demonstrated that continuous cisternal irrigation with $\mathrm{MgSO}_{4}$ solution decreases the rate of occurrence of CV in patients with SAH. How- ever, this improvement in $\mathrm{CV}$ onset did not reduce the incidence of DCI, and it also did not improve functional outcomes in our patients. Despite the observed reduction in $\mathrm{CV}$, which is the likely cause of DCI, the vasodilatory effect of $\mathrm{Mg}^{2+}$ on $\mathrm{CV}$ did not appear to improve the functional outcomes in this study. Prevention and aggressive treatment of pathological CV are certainly beneficial for patients with $\mathrm{SAH}$, so both require further clinical research. We propose that a prospective multicenter trial should be conducted to address this need for additional clinical data on $\mathrm{CV}$ in patients with $\mathrm{SAH}$.

\section{References}

1. Bulsara KR, Gunel M, Amin-Hanjani S, Chen PR, Connolly ES, Friedlander RM: Results of a national cerebrovascular neurosurgery survey on the management of cerebral vasospasm/delayed cerebral ischemia. J Neurointerv Surg, 2014

2. Cahill J, Zhang JH: Subarachnoid hemorrhage: is it time for a new direction? Stroke 40 (3 Suppl):S86-S87, 2009

3. Chia RY, Hughes RS, Morgan MK: Magnesium: a useful adjunct in the prevention of cerebral vasospasm following aneurysmal subarachnoid haemorrhage. J Clin Neurosci 9:279-281, 2002

4. Dankbaar JW, Rijsdijk M, van der Schaaf IC, Velthuis BK, Wermer MJ, Rinkel GJ: Relationship between vasospasm, cerebral perfusion, and delayed cerebral ischemia after aneurysmal subarachnoid hemorrhage. Neuroradiology 51:813819, 2009

5. Dorhout Mees SM: Magnesium in aneurysmal subarachnoid hemorrhage (MASH II) phase III clinical trial MASH-II study group. Int J Stroke 3:63-65, 2008

6. Dorhout Mees SM, Algra A, Vandertop WP, van Kooten F, Kuijsten HA, Boiten J, et al: Magnesium for aneurysmal subarachnoid haemorrhage (MASH-2): a randomised placebocontrolled trial. Lancet 380:44-49, 2012 (Erratum in Lancet 380:1994, 2012)

7. Dorsch NW: Therapeutic approaches to vasospasm in subarachnoid hemorrhage. Curr Opin Crit Care 8:128-133, 2002

8. Dreier JP, Major S, Manning A, Woitzik J, Drenckhahn C, Steinbrink J, et al: Cortical spreading ischaemia is a novel process involved in ischaemic damage in patients with aneurysmal subarachnoid haemorrhage. Brain 132:1866-1881, 2009

9. Etminan N, Vergouwen MD, Ilodigwe D, Macdonald RL: Effect of pharmaceutical treatment on vasospasm, delayed cerebral ischemia, and clinical outcome in patients with aneurysmal subarachnoid hemorrhage: a systematic review and meta-analysis. J Cereb Blood Flow Metab 31:1443-1451, 2011

10. Fergusen S, Macdonald RL: Predictors of cerebral infarction in patients with aneurysmal subarachnoid hemorrhage. Neurosurgery 60:658-667, 2007

11. Findlay JM, Weir BK, Steinke D, Tanabe T, Gordon P, Grace M: Effect of intrathecal thrombolytic therapy on subarachnoid clot and chronic vasospasm in a primate model of SAH. J Neurosurg 69:723-735, 1988

12. Frontera JA, Fernandez A, Schmidt JM, Claassen J, Wartenberg KE, Badjatia N, et al: Clinical response to hypertensive hypervolemic therapy and outcome after subarachnoid hemorrhage. Neurosurgery 66:35-41, 2010

13. Fujii M, Yan J, Rolland WB, Soejima Y, Caner B, Zhang JH: Early brain injury, an evolving frontier in subarachnoid hemorrhage research. Transl Stroke Res 4:432-446, 2013

14. Greenway DC, Hindmarsh JT, Wang J, Khodadeen JA, 
Hébert PC: Reference interval for whole blood ionized magnesium in a healthy population and the stability of ionized magnesium under varied laboratory conditions. Clin Biochem 29:515-520, 1996

15. Kassell NF, Torner JC, Jane JA, Haley EC Jr, Adams HP: The International Cooperative Study on the Timing of Aneurysm Surgery. Part 2: Surgical results. J Neurosurg 73:37-47, 1990

16. Keuskamp J, Murali R, Chao KH: High-dose intraarterial verapamil in the treatment of cerebral vasospasm after aneurysmal subarachnoid hemorrhage. J Neurosurg 108:458463, 2008

17. Kodama N: Cisternal irrigation with UK to prevent vasospasm. Surg Neurol 54:95, 2000 (Letter)

18. Lin JY, Chung SY, Lin MC, Cheng FC: Effects of magnesium sulfate on energy metabolites and glutamate in the cortex during focal cerebral ischemia and reperfusion in the gerbil monitored by a dual-probe microdialysis technique. Life Sci 71:803-811, 2002

19. Macdonald RL: Endothelin antagonists in subarachnoid hemorrhage: what next? Crit Care 16:171, 2012

20. Macdonald RL, Higashida RT, Keller E, Mayer SA, Molyneux A, Raabe A, et al: Clazosentan, an endothelin receptor antagonist, in patients with aneurysmal subarachnoid haemorrhage undergoing surgical clipping: a randomised, doubleblind, placebo-controlled phase 3 trial (CONSCIOUS-2). Lancet Neurol 10:618-625, 2011

21. Mocco J, Zacharia BE, Komotar RJ, Connolly ES Jr: A review of current and future medical therapies for cerebral vasospasm following aneurysmal subarachnoid hemorrhage. Neurosurg Focus 21(3):E9, 2006

22. Mori K, Miyazaki M, Hara Y, Aiko Y, Yamamoto T, Nakao Y: Novel vasodilatory effect of intracisternal injection of magnesium sulfate solution on spastic cerebral arteries in the canine two-hemorrhage model of subarachnoid hemorrhage. J Neurosurg 110:73-78, 2009

23. Mori K, Miyazaki M, Hara Y, Aiko Y, Yamamoto T, Nakao $Y$, et al: Temporal profile of the effects of intracisternal injection of magnesium sulfate solution on vasodilation of spastic cerebral arteries in the canine SAH model. Acta Neurochir Suppl 110:39-42, 2011

24. Mori K, Miyazaki M, Iwata J, Yamamoto T, Nakao Y: Intracisternal infusion of magnesium sulfate solution improved reduced cerebral blood flow induced by experimental subarachnoid hemorrhage in the rat. Neurosurg Rev 31:197203, 2008

25. Mori K, Yamamoto T, Miyazaki M, Hara Y, Aiko Y, Koike $\mathrm{N}$, et al: Effect of intrathecal magnesium sulfate solution injection via a microcatheter in the cisterna magna on cerebral vasospasm in the canine subarachnoid haemorrhage model. Br J Neurosurg 26:64-68, 2012

26. Mori K, Yamamoto T, Miyazaki M, Hara Y, Aiko Y, Koike $\mathrm{N}$, et al: Optimal cerebrospinal fluid magnesium ion concentration for vasodilatory effect and duration after intracisternal injection of magnesium sulfate solution in a canine subarachnoid hemorrhage model. J Neurosurg 114:1168-1175, 2011

27. Mori K, Yamamoto T, Nakao Y, Miyazaki M, Iwata J, Tamura M, et al: Novel neuroprotective effect of cisternal and intra-cerebral magnesium sulfate solution infusion on delayed cerebral death in rat hippocampal neurons after transient global ischemia. Brain Res 1480:72-80, 2012

28. Mori K, Yamamoto T, Nakao Y, Osada H, Hara Y, Oyama $\mathrm{K}$, et al: Initial clinical experience of vasodilatory effect of intra-cisternal infusion of magnesium sulfate for the treatment of cerebral vasospasm after aneurysmal subarachnoid hemorrhage. Neurol Med Chir (Tokyo) 49:139-145, 2009

29. Muir KW, Lees KR, Ford I, Davis S: Magnesium for acute stroke (Intravenous Magnesium Efficacy in Stroke trial): randomised controlled trial. Lancet 363:439-445, 2004

30. Muroi C, Terzic A, Fortunati M, Yonekawa Y, Keller E: Magnesium sulfate in the management of patients with aneurysmal subarachnoid hemorrhage: a randomized, placebocontrolled, dose-adapted trial. Surg Neurol 69:33-39, 2008

31. Odom MJ, Zuckerman SL, Mocco J: The role of magnesium in the management of cerebral vasospasm. Neurol Res Int 2013:943914, 2013

32. Rabinstein AA, Friedman JA, Weigand SD, McClelland RL, Fulgham JR, Manno EM, et al: Predictors of cerebral infarction in aneurysmal subarachnoid hemorrhage. Stroke 35:1862-1866, 2004

33. Sasaki T, Kodama N, Kawakami M, Sato M, Asari J, Sakurai Y, et al: Urokinase cisternal irrigation therapy for prevention of symptomatic vasospasm after aneurysmal subarachnoid hemorrhage: a study of urokinase concentration and the fibrinolytic system. Stroke 31:1256-1262, 2000

34. Schmid-Elsaesser R, Kunz M, Zausinger S, Prueckner S, Briegel J, Steiger HJ: Intravenous magnesium versus nimodipine in the treatment of patients with aneurysmal subarachnoid hemorrhage: a randomized study. Neurosurgery 58:1054-1065, 2006

35. Sehba FA, Pluta RM, Zhang JH: Metamorphosis of subarachnoid hemorrhage research: from delayed vasospasm to early brain injury. Mol Neurobiol 43:27-40, 2011

36. Shibuya M, Suzuki Y, Sugita K, Saito I, Sasaki T, Takakura $\mathrm{K}$, et al: Effect of AT877 on cerebral vasospasm after aneurysmal subarachnoid hemorrhage. Results of a prospective placebo-controlled double-blind trial. J Neurosurg 76:571577, 1992

37. Suzuki Y, Shibuya M, Satoh S, Sugimoto Y, Takakura K: A postmarketing surveillance study of fasudil treatment after aneurysmal subarachnoid hemorrhage. Surg Neurol 68:126132,2007

38. Takeuchi S, Mori K, Arimoto H, Fujii K, Nagatani K, Tomura S, et al: Effects of intravenous infusion of hydrogen-rich fluid combined with intra-cisternal infusion of magnesium sulfate in severe aneurysmal subarachnoid hemorrhage: study protocol for a randomized controlled trial. BMC Neurol 14:176, 2014

39. Turlapaty PD, Altura BM: Extracellular magnesium ions control calcium exchange and content of vascular smooth muscle. Eur J Pharmacol 52:421-423, 1978

40. van den Bergh WM, Algra A, van Kooten F, Dirven CM, van Gijn J, Vermeulen M, et al: Magnesium sulfate in aneurysmal subarachnoid hemorrhage: a randomized controlled trial. Stroke 36:1011-1015, 2005

41. van den Bergh WM, Dijkhuizen RM, Rinkel GJ: Potentials of magnesium treatment in subarachnoid haemorrhage. Magnes Res 17:301-313, 2004

42. van den Bergh WM, Zuur JK, Kamerling NA, van Asseldonk JT, Rinkel GJ, Tulleken CA, et al: Role of magnesium in the reduction of ischemic depolarization and lesion volume after experimental subarachnoid hemorrhage. J Neurosurg 97:416-422, 2002

43. Venkatasubba Rao CP, Suarez JI: Magnesium and neuroprotection in subarachnoid haemorrhage. Lancet 380:9-11, 2012

44. Vergouwen MD, Vermeulen M, Coert BA, Stroes ES, Roos YB: Microthrombosis after aneurysmal subarachnoid hemorrhage: an additional explanation for delayed cerebral ischemia. J Cereb Blood Flow Metab 28:1761-1770, 2008

45. Westermaier T, Stetter C, Vince GH, Pham M, Tejon JP, Eriskat J, et al: Prophylactic intravenous magnesium sulfate for treatment of aneurysmal subarachnoid hemorrhage: a randomized, placebo-controlled, clinical study. Crit Care Med 38:1284-1290, 2010

46. Wong GK, Boet R, Poon WS, Chan MT, Gin T, Ng SC, et al: 
Intravenous magnesium sulphate for aneurysmal subarachnoid hemorrhage: an updated systemic review and metaanalysis. Crit Care 15:R52, 2011

47. Wong GK, Poon WS: Clazosentan for patients with subarachnoid haemorrhage: lessons learned. Lancet Neurol 10:871872, 2011 (Letter)

48. Wong GK, Poon WS, Chan MT, Boet R, Gin T, Ng SC, et al: Intravenous magnesium sulphate for aneurysmal subarachnoid hemorrhage (IMASH): a randomized, double-blinded, placebo-controlled, multicenter phase III trial. Stroke 41:921-926, 2010

49. Yamamoto T, Esaki T, Nakao Y, Mori K: Efficacy of lowdose tissue-plasminogen activator intracisternal administration for the prevention of cerebral vasospasm after subarachnoid hemorrhage. World Neurosurg 73:675-682, 2010

\section{Author Contributions}

Conception and design: Yamamoto, Mori. Acquisition of data: Yamamoto, Esaki, Nakao, Tokugawa, Watanabe. Analysis and interpretation of data: Yamamoto. Drafting the article: Yamamoto. Critically revising the article: all authors. Reviewed submitted version of manuscript: all authors. Approved the final version of the manuscript on behalf of all authors: Yamamoto. Statistical analysis: Yamamoto. Study supervision: Mori.

\section{Correspondence}

Takuji Yamamoto, Department of Neurosurgery, Juntendo University Shizuoka Hospital, 1129 Nagaoka, Izunokuni-City, Shizuoka 410-2295, Japan. email: tyamamoto@med-juntendo.jp. 